\title{
Lease Receivables Information System Design: Case Study on PT. X During the Implementation of Work from Home
}

\author{
*Bobby Primananda Mulkanaz ${ }^{1}$, Setyo Hari Wijanto \\ ${ }^{1}$ Master of Accounting, University of Indonesia \\ ${ }^{2}$ Master of Accounting, University of Indonesia \\ *Corresponding author. E-mail: bob.bp93@gmail.com
}

\begin{abstract}
This study aims to analyze and design a lease receivables system at PT X, a company that offers heavy equipment leasing products to corporate customers. In carrying out its business administration processes, PT X uses a lot of documents, both those provided by the lessee and PT X's internal documents. Manual archiving of physical leasing documents are starting to be less effective due to the working from home provisions applied by PT X. To archive leasing documents, management PT X needs an information system design that can facilitate the archiving of documents appropriately. Then, PT X applies a manual process to the floating interest release process and the calculation of interest income. This research uses a case study approach with qualitative methods. Data were obtained through interview instruments, content analysis, and observation. The FAST (Framework for the Application of Systems Technique) method was used to design the lease receivables information system. The solution offered through this information system design is to provide a centralized information system design needed by company management to archive leasing documents and calculate floating interest rates and interest income regularly.
\end{abstract}

Keywords: Accounting Information System, Lease Receivables, Work from Home, Floating Interest Rate, Interest Income Calculation

\section{INTRODUCTION}

The business will continuously strive to improve the efficiency of its operating activities to achieve higher profitability. Information systems and technology are essential tools for management to achieve higher efficiency and productivity in business operations, especially when changes in business practices and management behaviour [1]. The Covid-19 pandemic has changed the traditional workplace culture that requires employees to come and work in the office. Currently, many companies require their employees to work from home to comply with government regulations regarding Covid-19 health procedures. To support business activities during the Covid-19 pandemic, it is undeniable that technology is one of the most influential factors, especially in maintaining employee performance. [2] in his research concluded that technology is a variable that can increase employee motivation at work during the Covid-19 pandemic.
PT $\mathrm{X}$ is a company engaged in financial services that offers leasing products, especially leasing for the purchase of heavy equipment. As one of the companies affected by the Covid-19 pandemic, PT X implements working from home (WFH) for its employees. In carrying out its business administration processes, PT X uses a lot of official documents, both those made by the lessee and PT X's internal documents or data. Before the Covid- 19 pandemic, these documents were printed and stored in physical archives and would usually be reaccessed when needed. However, since the commencement of the WFH instruction, these documents are increasingly being sent and received in the form of soft files. This was not a significant problem at first. However, as more and more leasing applications are processed using this method, procedures are as usual. Problems faced by PT X management are data redundancy, difficulties in monitoring the validation, review, and confirmation processes the 
difficulty of management in tracing the most recent version of the data.

In addition to the data problems above, PT X uses manual processes in several activities, including the floating interest release process and the interest income calculation process. Therefore, management needs an information system to solve data problems and facilitate both processes. This study aims to design an information system that can solve data problems in the lease receivables process to facilitate essential transaction processes at PT X.

This research question is how to design an information system that can overcome data problems (confidentiality, integrity, and availability) and facilitate essential transactions in the lease receivables process at PT X.

This research uses the Framework for the Application of System Thinking (FAST) method to design an information system. This method consists of eight steps, but this study uses only four steps: scope definition, problem analysis, requirement analysis, and logical design.

This research consists of five parts: introduction, literature review and theoretical framework, research methodology, research findings, discussion, and a conclusion.

\section{LITERATURE REVIEW THEORITICAL FRAMEWORK}

AND

\subsection{Lease}

Lease is a financing activity that involves two parties, the lessee and the lessor. A lessee is a company or individual that uses capital goods whose financing comes from the lessor. In contrast, the lessor is a company that provides financing services or leases goods to the lessee in a lease.

\subsection{Accounting Information System}

An accounting information system is a system that collects, records, stores, and processes data that aims to produce information for decision-makers. An organization's accounting information systems can be pen and paper manual systems, complex systems supported by the latest information technology, or a combination of manuals and information technology systems [3].

The point of view used in accounting information systems is being able to become an organization's central information system. It can provide users with the information needed to carry out their work. Accounting information systems can fulfill three essential business functions [3]:

1) Collect and store data on the organization's activities, resources, and personnel

2) Turning data into useful information for decision-makers in planning, executing, controlling, and evaluating their business activities

3) Provide adequate internal control for the security of the organization's assets and data

\subsection{FAST (Framework for the Application of Systems Thinking) Methodology}

The Framework for the Application of System Thinking is a reliable framework that is flexible enough to provide various types of projects and strategies in developing information systems [4]. Analysis within the FAST framework is structured, then object-oriented and design-oriented.

According to [4], FAST has been developed as a combination of best practices found in many commercial methodologies and other references. Unlike many other commercial methodologies, FAST is not prescriptive. FAST also integrates all popular systems analysis approaches. The FAST methodology consists of 8 stages, as illustrated in Figure 1.

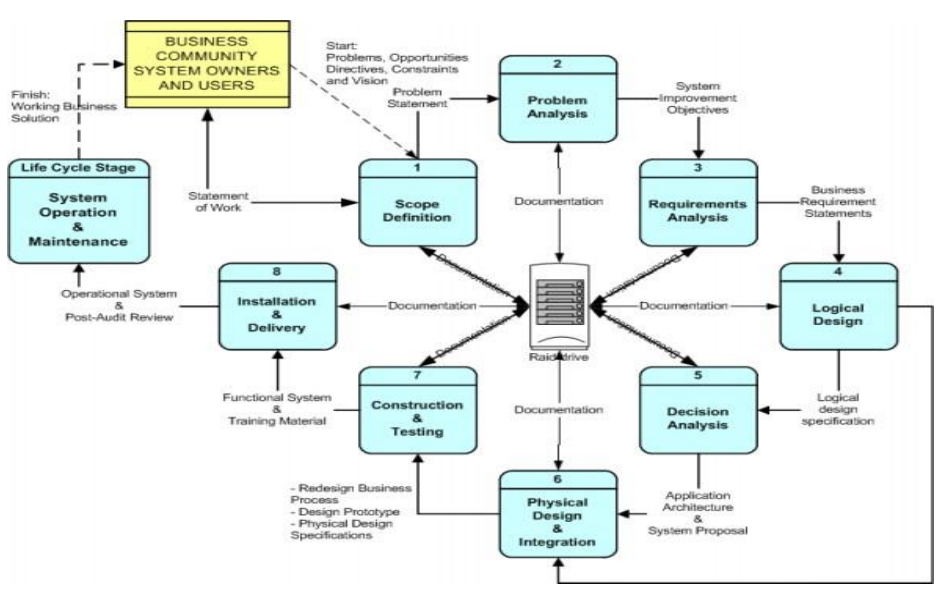

Figure 1. FAST Process Stage (Source: FAST Process Stage [4]) 
The following is an explanation of the eight stages of the FAST framework; according to [4], this study utilized the four early phases:

1) Scope Definition. This phase is the first stage of FAST. This phase aims to answer the question, "Is this problem worth looking at?". The PIECES (Performance, Information, Economics, Control, Efficiency, Service) framework can be used in this phase because, in general, it is very good at explaining problem statements.

2) Problems Analysis. This phase is the second phase of FAST. This phase studies the existing system, collects the findings and then analyzes it to understand the problems that triggered the project.

3) Requirements Analysis. This phase is the third stage of FAST. This phase determines the user and business requirements that will be accommodated in the new system. Analysis in this phase is done by approaching the user, which aims to determine what users need and want from the new system. The approach is carried out carefully to avoid mistakes in conducting the analysis. Requirements analysis can be described using a functional decomposition diagram. A functional decomposition diagram is a diagram that divides the system into subsystems or subprocesses displayed in more detail than the whole system [4]. The functional decomposition diagram is described in a hierarchical manner, which shows the system's top-down functions and structure.

4) Logical Design. This phase is the fourth stage of FAST. This phase converts user or business requirements into system modeling. System modeling is done by fulfilling the elements of completeness and consistency. System modeling also bridges good communication between users, systems analysts, system designers, and system builders. The form of system modeling is in the form of data flow diagrams. Next is a system analysis that can describe logical data models, logical system models, and their specifications.

\subsection{System Modelling}

\subsubsection{Data Flow Diagram (DFD)}

The data flow diagram is a diagram that describes the flow of data through the system and the processes carried out by the system [4]. The data flow diagram describes the data flow into and out of the system.

\subsubsection{Entity Relationship Diagram (ERD)}

In system development, there is a database modeling system. An entity-relationship diagram is a technique used to organize and document system data or database modeling.

The entity-relationship diagram consists of several parts, namely entity, relationship, and domain. Entity describes something that can be a person, object, place, concept, or event needed to store data. A relationship describes the business relationship between an entity and other entities. Attributes describe the descriptive characteristics of an entity [4].

\section{RESEARCH METHODOLOGY}

\subsection{Research Method}

This research is a case study research. Case studies are defined as research strategies carried out by carefully and precisely analyzing an event, process, activity, individual, or group limited by time and activity [5]. According to [6], the definition of a case study is a picture made based on reality or reality that makes the reader participate in the situation. This research uses a case study strategy because the research questions formulated are oriented to how to analyze and design an information system for lease receivables that is by the needs of PT X, so an in-depth analysis and information extraction can be answered through a case study research strategy.

This research approach uses qualitative research. Qualitative research is a holistic approach that involves discovering and allows researchers to develop in detail the phenomena that occur [5]. This research uses qualitative research because it can explain a phenomenon that occurs thoroughly and in detail.

\subsection{Data Collection}

The types of data used in this study are qualitative and quantitative data. Qualitative data is data in the form of verbal, while quantitative data is data in the form of numeric.

Sources of data are obtained from primary data and secondary data. Primary data is data obtained directly from sources, while secondary data is obtained from existing sources. In this study, primary data was obtained from the results of researcher interviews with resource persons and observations, while secondary data was obtained using content analysis from company internal reports and company documents relevant to this study. 


\subsection{Research Instrument}

This study uses three research instruments: interviews, content analysis, and observation. Interviews are used as an instrument in this study so that the authors obtain detailed and in-depth information. Interviews were conducted with internal parties of PT X, namely the Accounting Manager, Finance Manager, and Marketing Manager.

Content analysis is used as an instrument in this study to obtain and analyze relevant documents related to research questions. The definition of content analysis is a research instrument that interprets the documents obtained to provide relevant meaning according to the topic under study [7]. The documents analyzed in this study are PT X's internal documents relevant to answering research questions.

Observation is used as an instrument in this study to strengthen the study results and provide confidence in the activities that occur directly. Observations were carried out by directly observing the unit of analysis and were carried out actively regarding activities related to answering research questions.

\subsection{Data Analysis}

This research uses the FAST methodology to generate output in the form of lease receivables information system design. The data analysis technique used in this research is descriptive qualitative analysis. Descriptive qualitative data analysis is a technique used to describe the problems that occur in detail which aims to produce a picture of the data that has been obtained so that it can obtain results in the form of information about the problems that occur [8].

\subsection{Unit Analysis}

The research subject in this study is PT X, one of the companies engaged in finance leases for corporate consumers. PT X has been established and operating in Indonesia for more than eight years. PT $\mathrm{X}$ 's office is located in DKI Jakarta. The research subject focuses more on the units or departments of PT X related to leasing receivables activities. The unit of analysis used in this study is a single-unit analysis.

\section{RESEARCH FINDINGS}

\subsection{Scope Definition}

At this stage, the definition of the scope of system development, problems, and opportunities. Existing problems and opportunities will be categorized based on the PIECES frameworks. The problem statement and analysis of existing opportunities to know the scope of system development can be seen in table 1 .

Table 1. List of Problems and Opportunites (PIECES)

\begin{tabular}{|c|c|c|}
\hline No & Problems and Opportunities & Solutions \\
\hline \multicolumn{3}{|c|}{ Performance } \\
\hline 1. & $\begin{array}{l}\text { The process of reviewing the leasing application } \\
\text { takes a relatively long time. }\end{array}$ & $\begin{array}{l}\text { Development of a new system thatincludes a } \\
\text { centralized review of the lease receivables } \\
\text { process. }\end{array}$ \\
\hline \multicolumn{3}{|c|}{ Information and Data } \\
\hline 2. & Decentralized consumer data & $\begin{array}{l}\text { System development with a centralized } \\
\text { database. }\end{array}$ \\
\hline 3. & $\begin{array}{l}\text { Data regarding overall leasing is still in the form } \\
\text { of physical documents and it is difficult to access } \\
\text { documents that are already stored in the } \\
\text { archives. }\end{array}$ & $\begin{array}{l}\text { System development with a centralized } \\
\text { database. }\end{array}$ \\
\hline 4. & $\begin{array}{l}\text { Consumer historical data is not stored properly } \\
\text { and is not integrated. }\end{array}$ & $\begin{array}{l}\text { System development with a centralized } \\
\text { database. }\end{array}$ \\
\hline
\end{tabular}




\begin{tabular}{|l|l|l|}
\hline 5. & $\begin{array}{l}\text { Opportunity to reduce administrative cost in } \\
\text { thelong run. }\end{array}$ & \multicolumn{1}{l|}{$\begin{array}{l}\text { System development that can reduce the } \\
\text { use ofphysical documents. }\end{array}$} \\
\hline \multicolumn{3}{|c|}{ Control and Security } \\
\hline 6. & $\begin{array}{l}\text { Reducing the risk of fraud in the leasing } \\
\text { application and approval process. }\end{array}$ & $\begin{array}{l}\text { System development that can reduce the } \\
\text { use ofphysical documents. }\end{array}$ \\
\hline Efficiency & $\begin{array}{l}\text { System development that can reduce the } \\
\text { use ofphysical documents. }\end{array}$ \\
\hline otherstationery. \\
\hline Service & $\begin{array}{l}\text { The existing system is still done manually and } \\
\text { isrunning less effectively and efficiently with } \\
\text { changes in current business processes. }\end{array}$ & $\begin{array}{l}\text { System development with a centralized } \\
\text { databasethat also facilitates important } \\
\text { activities. }\end{array}$ \\
\hline
\end{tabular}

\subsection{Problems Analysis}

During the Covid-19 pandemic, the existence of an information system is very much needed to facilitate employees so that they can continue to collaborate with teams and divisions. The leasing registration process that requires physical documents is also difficult for employees, especially during this pandemic period, where employees work alternately in their respective offices and at home. With this lease receivables information system, it is expected that company employees can work from home online without the need to go to the office. With the information system, relevant data and documents can be stored and accessed from within the system. Control in the leasing process can also be implemented through a review process by managers and directors.

\subsection{Requirements Analysis}

\subsubsection{Functional Decomposition Diagram (FDD)}

Requirements Analysis can be described by Functional Decomposition Diagram (FDD). The decomposition diagram shows the top-down process of functional decomposition or system structure. FDD is the first step in making a flow chart. Later, Context Data Flow Diagrams and Data Flow Diagrams (DFD) can be made from the compiled FDD.

Figure 2 shows the Functional composition decomposition diagram in the lease receivables information system design, divided into 8 (eight) subsystems, as follows: 1. Lessee Information Subsystem, 2. Leasing Registration Subsystem, 3. Disbursement Subsystem, 4. Invoice and Installment Receipt Subsystem, 5. Floating Interest Subsystem, 6. Restructuring Subsystem, 7. Termination Subsystem, 8. Management Report Subsystem. The subsystem is divided based on the PT X activities or transactions in the process of lease receivables. 


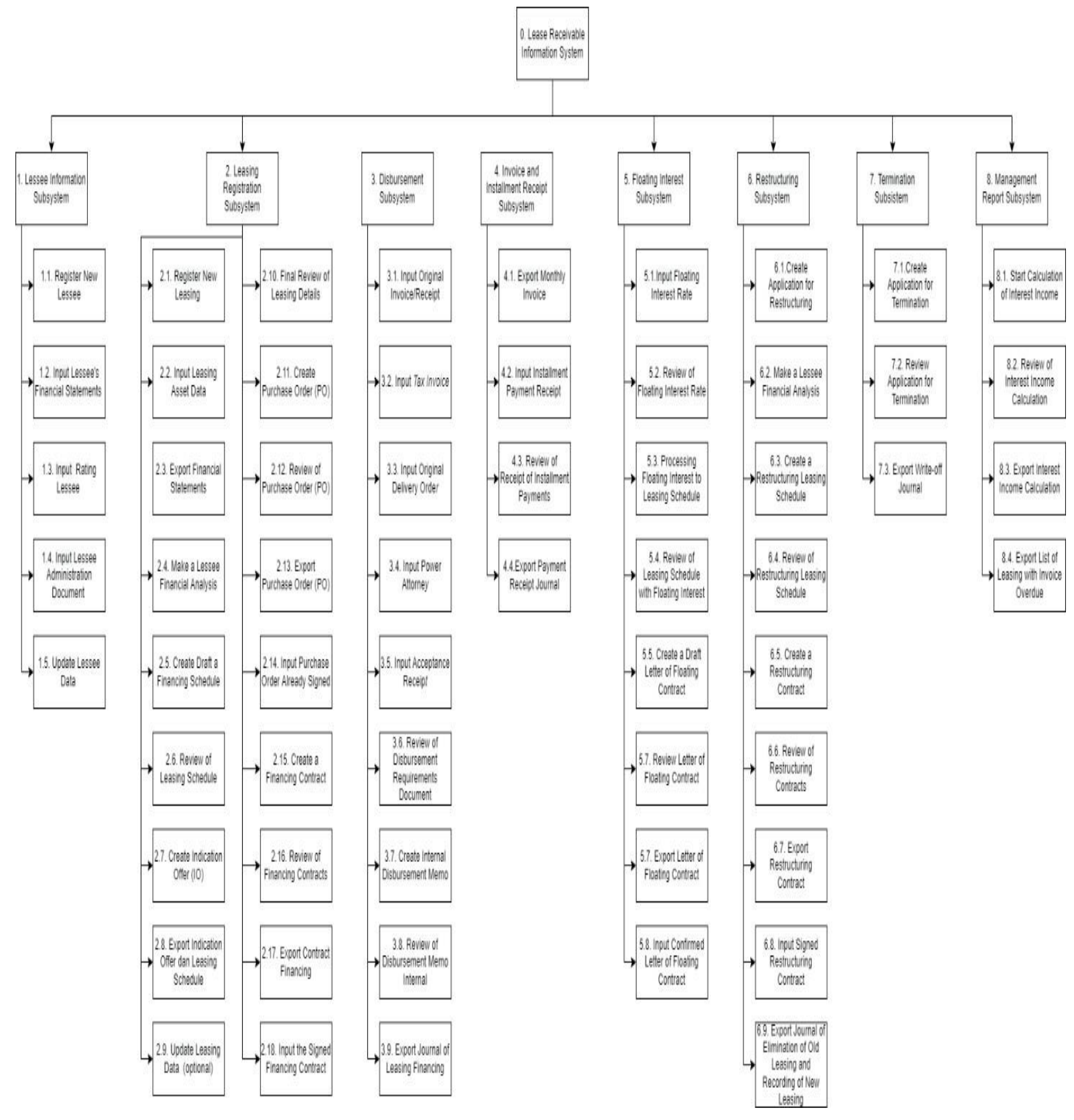

Figure 2. Functional Decomposition Diagram

\subsection{Logical Design}

\subsubsection{Data Flow Diagram (DFD)}

In the fourth stage of FAST, the logical design documenting the business requirements using a

system model that describes the data structure to validate the requirements defined in the previous stage. Documentation of data flow in the lease receivables information system, contextual data flow diagrams can be seen in Figure 3. 


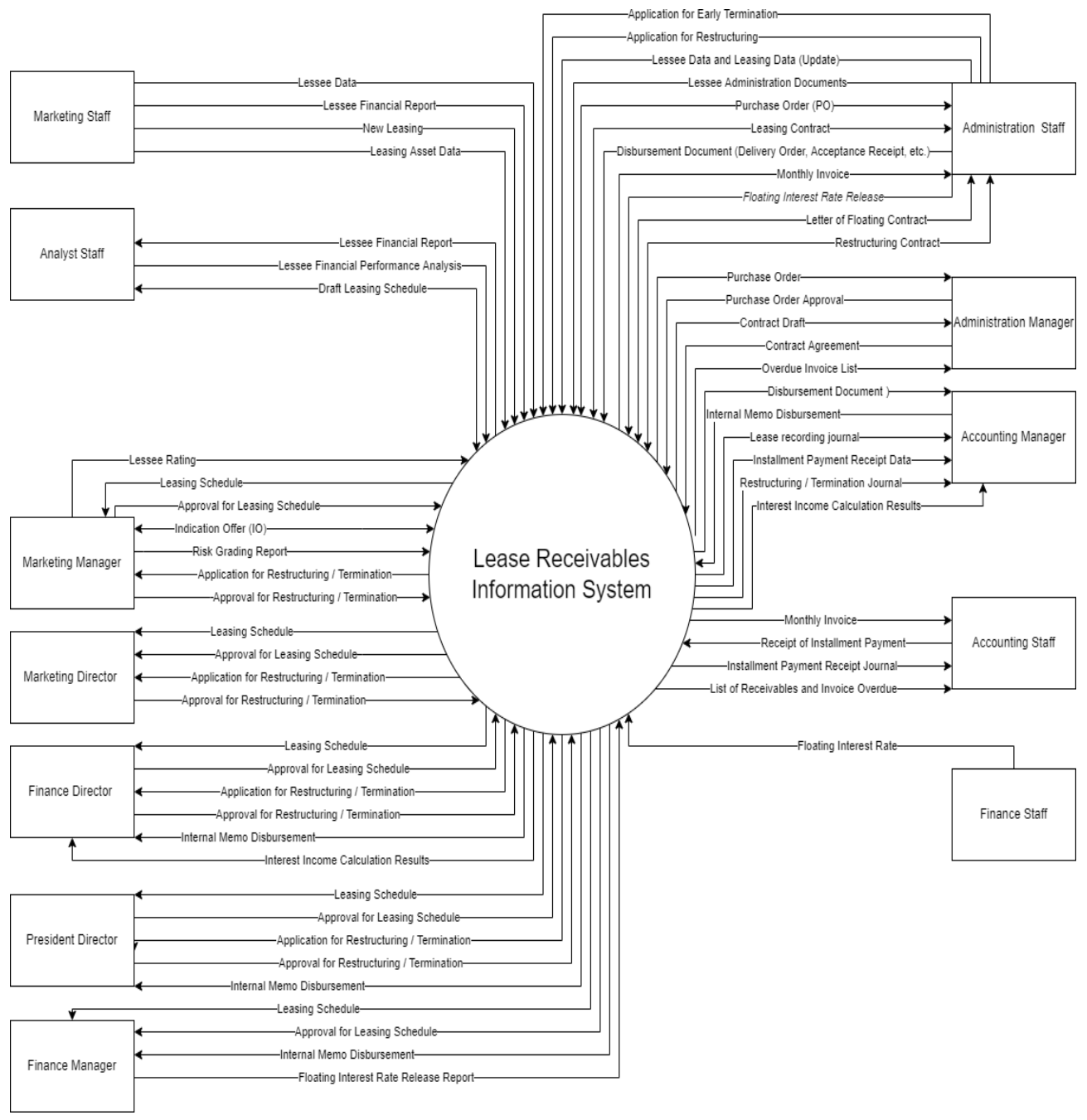

Figure 3. Contextual Data Flow Diagram

To design a system model, the first thing to do is document the initial project's scope. According to [4], the project scope describes what business aspects should be supported by the system or how the system interacts with other systems and the business as a whole. This is documented with a context data flow diagram. Figure 3 illustrates the context data flow diagram for a lease receivables information system.

\subsubsection{Entity Relationship Diagram (ERD)}

Lease receivables information systems ERD is shown in Figure 4. All data stored consists of attributes listed in all the entities shown in the ERD. Entity-relationship diagrams use several cardinality notations used to describe data in entities and the relationships described by these data. Cardinality notations define the number of occurrences of either one entity that can be associated with another entity [4]. There is a graphic notation in the cardinality notations. The following Table 2 . is a table that contains the interpretation of cardinality and its graphic notation. 


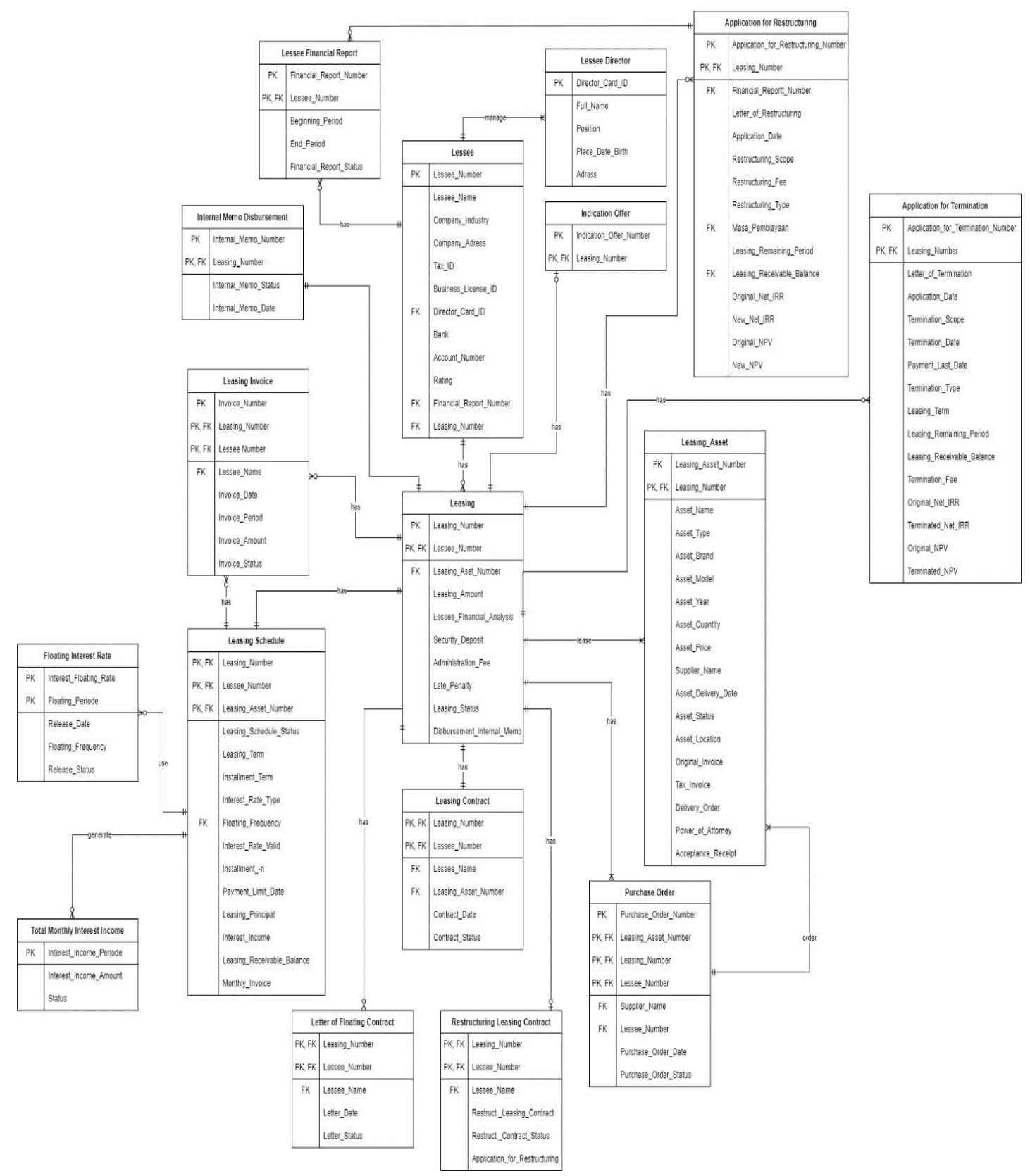

Figure 4. Entity Relationship Diagrams

\section{DISCUSSION}

The research question is how to design an information system that can overcome data problems (confidentiality, integrity, and availability) and can facilitate essential transactions in the lease receivables process at $\mathrm{PT} \mathrm{X}$. To answer these research questions; this study uses the Framework for the Application of System Thinking (FAST) in designing the required system.

In designing a system, the first step is to use a Functional Decomposition Diagram to divide the system into subsystems or logical functions. A subsystem is a group of tasks in the lease receivables PT X. There are eight subsystems and activities or transactions carried out. This study chose the Functional Decomposition Diagram as the first model because of its ability to provide a big picture of the system's functioning and is easy to understand.

Furthermore, the process modeling is shown using contextual diagrams. The contextual diagram is a data flow diagram that shows the big picture of the system. The one process in the context diagram can then be described as a Level 1 DFD.

The last system modeling is the data schema. This study uses an entity-relationship diagram to 
explain the data schema, which summarizes the data storage attributes displayed in the data flow diagram. The entity-relationship diagram describes the relationship and cardinality between the system's entities.

\section{CONCLUSION}

The lease receivables information system is designed based on the needs of PT X's management for an information system that can solve administrative problems at PT X. A lease receivables information system is also needed to facilitate essential processes needed in the lease business process at PT X. From the results of the analysis and in designing this lease receivables information system, the following conclusions are obtained:

1) PT X, in carrying out its business processes during the Covid-19 pandemic, faced several problems in terms of lease data management, including data confidentiality, data integrity, and data availability. The lease receivables information system has been analyzed and designed to address these data management problems so that data and documents related to the lease can be processed safely (confidentiality), not redundant (data integrity), and can be accessed according to management needs (availability).

2) In the leasing business process of PT X, several essential processes are still carried out manually, one of which is the calculation of leasing interest income. The lease receivables information system has been designed to assist the interest calculation process to be carried out more efficiently and with a more guaranteed level of accuracy.

This is in line with research conducted by [9] which concludes that an integrated system has the maximum impact on the benefits of company empowerment. In addition, [10] research explains that systems that can integrate business functions within the company can improve data access quickly and precisely. The system can also improve the company's performance by reducing the company's operational costs.

Two suggestions can be used for further research. The first is to develop a physical or website-based system; the second is to enlarge the scope of research by incorporating tools and management requirements of other processes into the system.

\section{AUTHORS' CONTRIBUTIONS}

The First Author, Bobby Primananda Mulkanaz Carry OutResearch Concept, Research Question, Conducting Research, System Design and Write the Manuscript. The Second Author, Setyo Hari Wijanto As Research Supervisor and Reviews the SystemDesign.

\section{ACKNOWLEDGMENTS}

In Arranging This Research, TheAuthors Are Grateful to The Research Supervisor Who Have Guided and Reviewed This Research. The Author Also thanks to Family and Friends Who Always Provide Motivation to The Author. The Author Also thanks to Employees of $\mathrm{Pt} \mathrm{X}$, Especially the Marketing and Finance Department WhoHave Been to Be Observed and Interviewed in This Study.

\section{REFERENCES}

[1] K. C. Laudon and J. P. Laudon, Management Information Systems 13th edition: Managing the Digital Firm. Prentice Hall.

[2] I. K. S. SAPTA, M. MUAFI, and N. M. SETINI, "The Role of Technology, Organizational Culture, and Job Satisfaction in Improving Employee Performance during the Covid-19 Pandemic," J. Asian Financ. Econ. Bus., vol. 8, no. 1, pp. 495-505, 2021.

[3] M. B. Romney and P. L. Steinbart, Accounting Information Systems, 14th ed. New Jersey: Pearson.

[4] R. N. Patton, System Analysis and Design Method, no. 7. New York: McGraw-Hill Company., 2007.

[5] J. W. Creswell, Research design: qualitative \& quantitative approaches. Sage Publications, 1994.

[6] W. Ellet, "The Case Study Handbook: How to Read, Discuss, and Write Persuasively about Cases."

[7] G. A. Bowen, "Document analysis as a qualitative research method," Qual. Res. J., vol. 9, no. 2, pp. 27-40, 2009.

[8] W. Neuman, Social Research Methods: Qualitative and Quantitative. Approaches, Seventh Ed. Pearson Education Limited., 2014. 
[9] S. Rouhani and M. Mehri, "Empowering benefits of ERP systems implementation: empirical study of industrial firms," J. Syst. Inf. Technol., vol. 20, no. 1, pp. 54-72, 2018.
[10] Z. J. H. Tarigan, H. Siagian, and P. Sebayang, "The impact of implementing enterprise resources planning (ERP) project on firm performance and organizational citizenship behavior as a moderating," $J$. Proj. Manag., vol. 5, pp. 227-236, 2020. 